J. Lake Sci. (湖泊科学), 2012, 24(5): 789-796

http: //www.jlakes.org. E-mail : jlakes@niglas.ac.cn

(C) 2012 by Journal of Lake Sciences

\title{
贵州红枫湖沉积物磷赋存形态的空间变化特征”
}

\author{
王敬富 ${ }^{1,2}$, 陈敬安 ${ }^{1 * *}$, 曾 艳 ${ }^{1,2}$,杨永琼 ${ }^{1,2}$, 杨海全 ${ }^{1,2}$ \\ (1: 中国科学院地球化学研究所环境地球化学国家重点实验室,贵阳 550002) \\ (2: 中国科学院研究生院, 北京 100049)
}

\begin{abstract}
摘 要: 选取贵州省红枫湖这一典型的亚深水型人工湖泊作为对象, 研究了 6 个代表性湖区沉积物柱芯磷的赋存形态, 结合水体温度和溶解氧现场监测结果, 探讨了该类型湖泊沉积物内源磷释放风险. 研究结果表明, 红枫湖沉积物总磷含 量普遍较高, 表层沉积物总磷含量均值大于 $1500 \mathrm{mg} / \mathrm{kg}$, 明显高于下部沉积物. NaOH-SRP 和 rest-P 是沉积物磷的主要赋 存形态. $\mathrm{NH}_{4} \mathrm{Cl}-\mathrm{P}$ 和 BD-P 含量表层最高, 随深度增加明显降低, rest-P 含量在垂向上变化不大. 人为活动是造成沉积物总 磷及赋存形态空间分布差异的主要原因, 工业废水和网箱养鱼活动等大大增加了沉积物 NaOH-SRP 含量. 红枫湖深水湖 区底部水温多在 $14.5 \sim 23.5^{\circ} \mathrm{C}$ 之间, 随季节变化底部水温差异明显, 溶解氧含量通常不高于 $1.5 \mathrm{mg} / \mathrm{L}$, 整体处于季节性 缺氧或厌氧状态. 以 NaOH-SRP 为主的沉积物磷赋存形态和深水缺氧环境大大增加了红枫湖沉积物内源磷释放的风险, 在未来的研究中函待加强对该类型湖泊沉积物内源磷释放机制、控制因素及治理措施的研究.
\end{abstract}

关键词: 红枫湖;沉积物;磷形态;温度;溶解氧

\section{Spatial distribution characteristics of phosphorus forms in sediment of Lake Hongfeng, Guizhou Province}

\author{
WANG Jingfu ${ }^{1,2}$, CHEN Jing' ${ }^{1}{ }^{1}$, ZENG Yan $^{1,2}$, YANG Yongqiong ${ }^{1,2}$ \& YANG Haiquan ${ }^{1,2}$ \\ (1: State Key Laboratory of Environmental Geochemistry, Institute of Geochemistry, Chinese Academy of Sciences, Guiyang \\ 550002 , P. R. China) \\ (2: Graduate University of Chinese Academy of Sciences, Beijing 100049, P. R. China)
}

\begin{abstract}
Lake Hongfeng is a man-made deep lake. Phosphorus of sediment samples that were collected from representative six water areas were analyzed. Water temperature and dissolved oxygen were investigated four times in the field by multi-parameter water quality observation analyzer YSI. The results showed that total phosphorus in sediment was generally high. The average value of total phosphorus in surface sediment was more than $1500 \mathrm{mg} / \mathrm{kg}$, significantly higher than that in the bottom sediments. NaOH$\mathrm{SRP}$ and rest-P were the main forms of phosphorus in sediment. $\mathrm{NH}_{4} \mathrm{Cl}-\mathrm{P}$, BD-P and HCl-P contents decreased with depth, and rest-P contents were stabile in vertical. Human activities (e. g. chemical waste water and artificial fish) greatly increased NaOHSRP contents in sediment. Temperature of bottom water was between $14.5-23.5^{\circ} \mathrm{C}$, and the maximum temperature differences was $9.9^{\circ} \mathrm{C}$ in different seasons. The bottom water was seasonal anoxic or anaerobic, which may result in changes of sediment phosphorus forms. Risk of endogenous phosphorus release increased due to anoxic condition of sediment-water interface in deep lake. Keywords: Lake Hongfeng; sediment; phosphorus forms; temperature; dissolved oxygen
\end{abstract}

湖泊富营养化是当前我国面临的最重要的水环境问题之一. 磷是湖泊初级生产的限制性营养元素 ${ }^{[1-2]}$, 在浮游植物的生长过程中起着极其重要的作用. 国内外湖泊的长期研究和观测结果表明, 尽管外源污染治 理使得污染物输人量大大减少, 但湖泊水体磷酸盐浓度并未像预期那样显著降低, 沉积物内源磷释放被认 为是导致这一现象的主要原因 ${ }^{[1-7]}$. 尤其是在湖水存在季节性分层而导致底层滞水带缺氧的亚深水型湖泊,

* 国家自然科学基金项目 (41021062)、国家科技支撑计划项目 (2011BAC02B0201) 和贵阳市科技计划项目联合资 助. 2011-10-25 收稿;2012-01-04 收修改稿. 王敬富,男,1983 年生,博士研究生;E-mail: geoolivine@ 126. com.

** 通信作者; E-mail:chenjingan@ vip. skleg. cn. 
沉积物内源磷释放对水体磷循环和水质有着更为重要的影响, 某些湖泊的内源磷释放对水体磷酸盐的贡献 超过了外源磷输人的影响 ${ }^{[4-5,8]}$.

研究沉积物磷赋存形态变化是揭示沉积物内源磷释放机制和影响因素的重要途径,也是湖泊沉积物一 水界面营养盐生物地球化学循环研究的重要内容. 在已有的沉积物磷赋存形态分析方法中,化学连续提取 法具有操作简便、适应大批量样品快速测定的显著特点,被不断改进和应用于海洋沉积物、淡水湖泊沉积物 磷赋存形态的研究 ${ }^{[9-15]}$.

深水一亚深水型湖泊沉积物一水界面溶解氧通常较低 ${ }^{[16-18]}$, 在缺氧条件下沉积物磷更易于释放,但目前有 关沉积物磷赋存形态对磷释放的控制及影响因素的研究仍显薄弱. 本文选取贵州省红枫湖这一典型的亚深水 型湖泊开展沉积物磷赋存状态空间变化研究, 旨在深化对亚深水型湖泊磷释放机制和控制因素的认识.

\section{1 材料与方法}

\section{1 研究区概况}

红枫湖地处贵州高原中部，位于清镇市、平坝县和安顺市西秀区境内（2626' $\left.26^{\circ} 35^{\prime} \mathrm{N}, 106^{\circ} 19^{\prime} \sim 106^{\circ} 28^{\prime} \mathrm{E}\right)$. 该湖泊是一座高原人工河道湖泊, 于 1960 年 5 月建成蓄水,流域面积 1596 $\mathrm{km}^{2}$, 水面面积 $57.2 \mathrm{~km}^{2}$. 湖泊长 $16 \mathrm{~km}$, 平均宽 $4 \mathrm{~km}$, 最大水深 $45 \mathrm{~m}$, 平均水深 $10.5 \mathrm{~m}$, 总库容 $6.01 \times 10^{8}$ $\mathrm{m}^{3}$, 主要的人湖河流包括麻线河、羊昌河、桃花源河、麦包河等 ${ }^{[18]}$. 红枫湖是贵州省贵阳市主要饮用水源, 兼 具发电、防洪、旅游、工农业用水、调节生态环境等多种功能. 流域出露地层以二叠系、三叠系为主, 碳酸盐岩 广泛分布,岩溶地貌发育,主要土壤类型为石灰土、黄壤和水稻土.

\section{2 样品采集与分析}

1.2 .1 沉积物样品 根据沉积物污染程度 ${ }^{[19]}$ 、湖泊补给及人为污染分布, 选取桃花源河 $(\mathrm{THY}) 、$ 羊昌河 $(\mathrm{YC})$ 、北湖中部 $(\mathrm{NM})$ 、南湖中部 $(\mathrm{SM})$ 、后五 $(\mathrm{HW})$ 和大坝 (Dam) 6 个代表性采样点 (图 1 ). 利用无扰动沉 积物采样装置采集沉积物柱芯 ${ }^{[20]}$, 按 $2 \mathrm{~cm}$ 进行分样, 对获取的沉积物样品, 采用真空冷冻干燥仪 ( Techconp FD-3-85-MP) 冷冻干燥. 干燥后的样品用玛瑙研钵研磨至 120 目以下,装于样品袋中备用.

1.2.2 磷形态提取及测定 采用 Hupffer 等发展建立的沉积物磷形态化学连续提取法 ${ }^{[11]}$, 将沉积物中的磷 分为五种形态,具体步骤为: (1) $1 \mathrm{~mol} / \mathrm{L} \mathrm{NH}_{4} \mathrm{Cl}$ 在 $\mathrm{pH}=7$ 条件下震荡 $0.5 \mathrm{~h}$, 提取 $\mathrm{NH}_{4} \mathrm{Cl}-\mathrm{P}$; (2) $0.11 \mathrm{~mol} / \mathrm{L}$ $\mathrm{NaHCO}_{3} / 0.11 \mathrm{~mol} / \mathrm{L} \mathrm{Na}_{2} \mathrm{~S}_{2} \mathrm{O}_{4}$, 即 BD 溶液, 震荡 $1 \mathrm{~h}$, 提取 BD-P; ( $\left.3 \mathrm{a}\right) 1 \mathrm{~mol} / \mathrm{L} \mathrm{NaOH}$, 震荡 $16 \mathrm{~h}$, 提取 $\mathrm{NaOH}-\mathrm{SRP}$; (3b) $3 \mathrm{a}$ 步骤中的提取液利用过硫酸钾溶液消解后测定其总磷含量, 此值与 NaOH-SRP 的差值 为 $\mathrm{NaOH}-\mathrm{NRP}$; (4) $0.5 \mathrm{~mol} / \mathrm{L} \mathrm{HCl}$ 震荡 $16 \mathrm{~h}$, 提取 HCl-P; (5) 残渣在 $500^{\circ} \mathrm{C}$ 条件下灰化 $2 \mathrm{~h}, 3.5 \mathrm{~mol} / \mathrm{L} \mathrm{HCl}$ 震荡 $16 \mathrm{~h}$, 提取 rest-P. 磷形态分级方法是根据不同提取剂和提取条件进行的分类, 并不是严格意义上的化 学分类,上述方法中各种磷形态的具体含义见表 1 .

表 1 沉积物磷赋存形态的化学连续提取方法 ${ }^{[11]}$

Tab. 1 Sequence chemistry extraction method of phosphorus forms in sediment

\begin{tabular}{|c|c|}
\hline 提取剂 & 所提取的磷形态 \\
\hline a. $1 \mathrm{~mol} / \mathrm{L} \mathrm{NH}_{4} \mathrm{Cl}$ & 孔隙水中松散吸附在物质表面的 (如铁和 $\mathrm{CaCO}_{3}$ 表面) 立即可用的磷, 即弱吸附态磷 \\
\hline b. $0.11 \mathrm{~mol} / \mathrm{L} \mathrm{BD}$ & 氧化还原敏感的磷,主要指被铁的氢氧化物和锰的化合物约束的磷 \\
\hline c. $1 \mathrm{~mol} / \mathrm{L} \mathrm{NaOH}$ & $\begin{array}{l}\mathrm{SRP} \text { : 可与 } \mathrm{OH}^{-} \text {离子进行交换的铁铝金属氧化物约束的磷, 无机磷化合物, 主要为铁铝结合态磷; } \\
\mathrm{NRP} \text { : 微生物磷,包括碎屑中有机磷和聚磷, 以及腐殖酸化合物结合的磷 }\end{array}$ \\
\hline d. $0.5 \mathrm{~mol} / \mathrm{L} \mathrm{HCl}$ & 碳酸盐结合的磷和磷灰石磷,微量的水解有机磷, 主要为钙结合态磷 \\
\hline $\begin{array}{l}\text { e. } 500^{\circ} \mathrm{C} \text { 灰化 } 2 \mathrm{~h} \\
3.5 \mathrm{~mol} / \mathrm{L} \mathrm{HCl}\end{array}$ & 有机磷和其他耐火物质中的磷 ～～～～ \\
\hline
\end{tabular}

注: SRP 为溶解性活性磷; NRP 为非活性磷, 即总磷与 SRP 的差值.

1.2 .3 水体理化参数原位监测 利用美国 YSI 公司生产的多参数水质监测仪 (YSI 6600 型), 分别于 2010 年 12 月,2011 年 $5 、 7$ 和 9 月按季节对红枫湖水体温度和溶解氧等理化参数进行野外监测. 水质监测仪测量的 


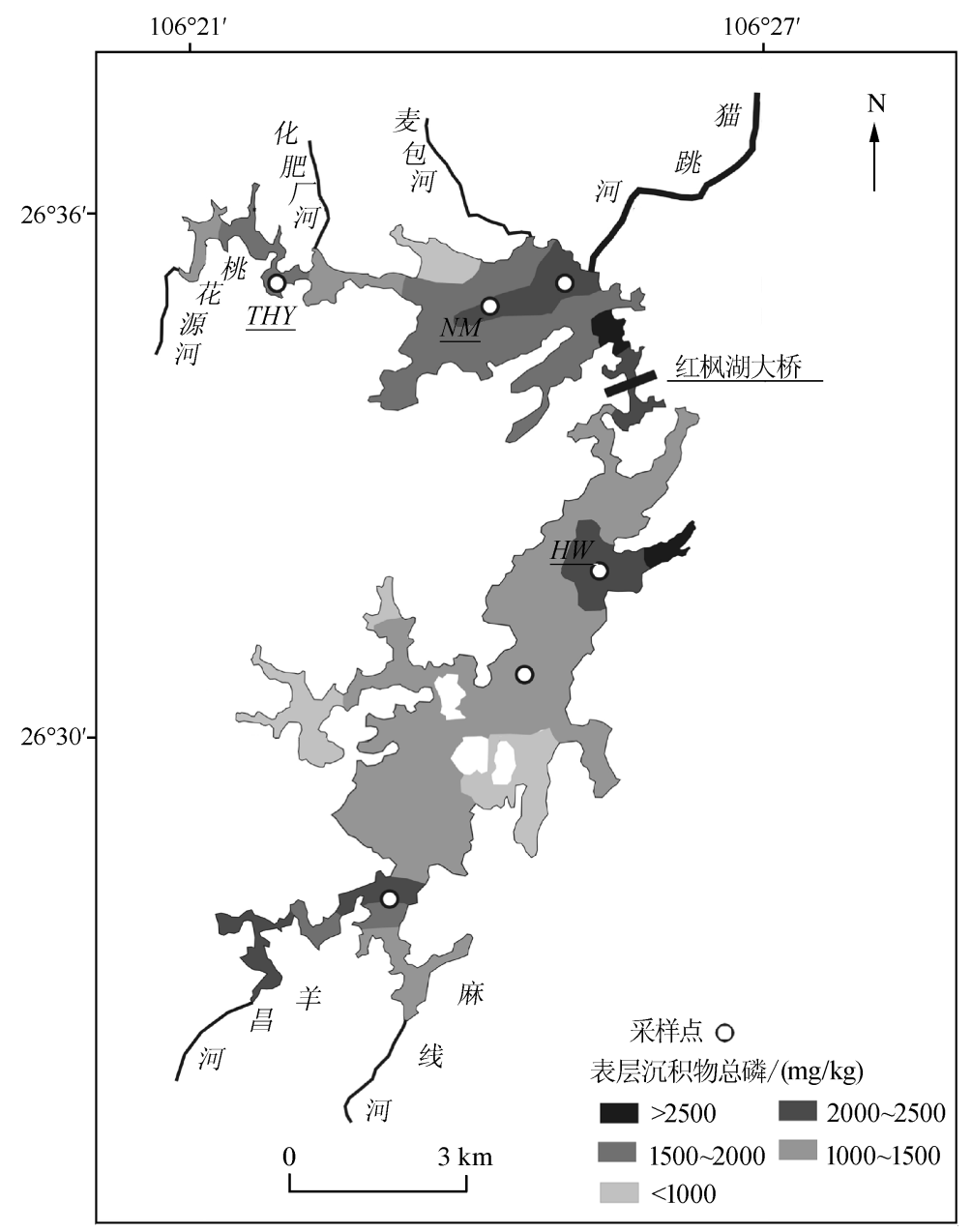

图 1 红枫湖采样点位置(底图(表层沉积物总磷的空间分布)引自文献[19])

Fig. 1 Location of sampling sites in Lake Hongfeng

温度范围为 $5 \sim 50^{\circ} \mathrm{C}$, 误差为 $\pm 0.15^{\circ} \mathrm{C}$, 溶解氧测量范围为 $0 \sim 20 \mathrm{mg} / \mathrm{L}$, 误差为 $\pm 2 \%$.

\section{2 结果与分析}

\section{1 红枫湖沉积物磷赋存形态的剖面变化特征}

红枫湖沉积物磷赋存形态的测定结果表明 (图 2), 沉积物总磷在水平和垂向上均存在差异. 污染最严重 的湖区是原人工养鱼的后五湖区和全湖出口的大坝湖区. 南湖人湖河流羊昌河沉积物磷负荷较重,而北湖 支流桃花源河的化肥厂上游河段沉积物磷负荷轻. 从整体来看, 红枫湖沉积物总磷含量表层明显高于底部, 呈现随深度增加而降低的趋势.

后五湖区受 20 世纪网箱养鱼和周边清镇电厂废水排放的影响, 沉积物总磷含量在 $293.1 \sim 2299.9 \mathrm{mg} / \mathrm{kg}$ 之间, 明显高于其他湖区. 在剖面深度约 $21 \mathrm{~cm}$ 处, 沉积物总磷含量由 $779.7 \mathrm{mg} / \mathrm{kg}$ 陡然升高至 $1921.2 \mathrm{mg} / \mathrm{kg}$. 上部沉积物总磷含量均值为 $1932.0 \mathrm{mg} / \mathrm{kg}$, 表层略低, 下部沉积物总磷含量均值仅为 $451.6 \mathrm{mg} / \mathrm{kg}$. 上部沉 积物磷以 NaOH-SRP 为主, 占沉积物总磷的 $51.2 \% \sim 67.2 \%$, 均值为 $1190.5 \mathrm{mg} / \mathrm{kg}$. 下部沉积物中 NaOH-SRP 均值仅为 $184.8 \mathrm{mg} / \mathrm{kg}$, 占沉积物总磷的 $38.3 \%$. NaOH-NRP 均值为 $32.9 \mathrm{mg} / \mathrm{kg}$, 约占总磷的 $6.8 \%, \mathrm{rest}-\mathrm{P}$ 均 值 $107.2 \mathrm{mg} / \mathrm{kg}$, 约占总磷的 $21.5 \%$.

大坝湖区沉积物总磷含量在 $639.9 \sim 2056.3 \mathrm{mg} / \mathrm{kg}$ 之间, 表层沉积物总磷含量明显高于底部沉积物. 沉 

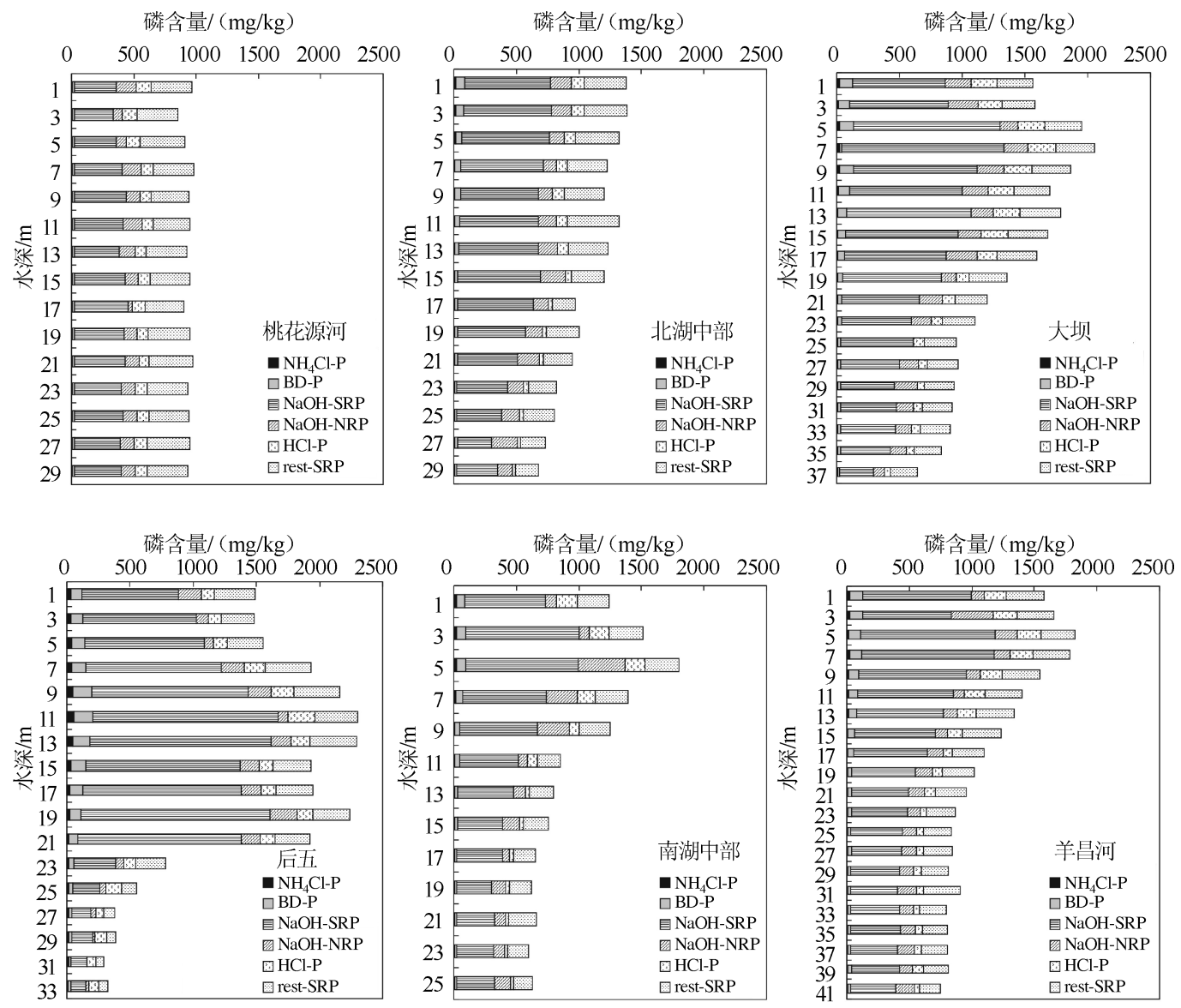

图 2 红枫湖沉积物磷赋存形态的剖面分布特征

Fig. 2 Vertical distribution of sediment phosphorus forms in Lake Hongfeng

积物总磷含量在表层 $5 \mathrm{~cm}$ 左右达到最大值, $5 \sim 20 \mathrm{~cm}$ 呈现明显的降低趋势, $20 \mathrm{~cm}$ 深度以下沉积物总磷含 量基本稳定在 $800 \mathrm{mg} / \mathrm{kg}$ 左右. NaOH-SRP 和 rest-P 是沉积物磷的主要赋存形态, 两者之和占沉积物总磷的 $76.7 \% \sim 89.0 \%$,均值 $84.3 \%$. rest-P 含量在 $213.2 \sim 322.9 \mathrm{mg} / \mathrm{kg}$ 之间, 绝对含量在剖面上变化不大. HCl-P、 BD-P 和 $\mathrm{NH}_{4} \mathrm{Cl}-\mathrm{P}$ 含量随深度增加明显降低,表层沉积物中含量最高. 沉积物总磷含量在垂向上的变化主要 是由 NaOH-SRP 含量变化引起的. 与大坝沉积物类似,南湖中部、北湖中部和羊昌河沉积物磷的组成亦以 NaOH-SRP 和 rest-P 为主. 其中, 羊昌河沉积物总磷含量在 $751.3 \sim 1824.8 \mathrm{mg} / \mathrm{kg}$ 之间, 略低于大坝沉积物. $\mathrm{NaOH}-\mathrm{SRP}$ 是沉积物磷的最主要形态,占沉积物总磷的 $41.0 \% \sim 59.3 \%$,均值 $50.5 \%$. rest-P 含量在 $170.7 \sim$ $315.0 \mathrm{mg} / \mathrm{kg}$ 之间,在剖面上变化不大.

北湖主要支流桃花源河的化肥厂上游河段沉积物污染轻, 沉积物总磷含量在 $851.0 \sim 973.7 \mathrm{mg} / \mathrm{kg}$ 之 间. NaOH-SRP 是沉积物磷的主要赋存形态, 占总磷的 $38.4 \%$. 其次, $\mathrm{NaOH}-\mathrm{NRP}$ 均值为 $111.5 \mathrm{mg} / \mathrm{kg}$, 约占总 磷的 $11.3 \%$, rest $-\mathrm{P}$ 均值为 $327.2 \mathrm{mg} / \mathrm{kg}$, 约占总磷的 $33.0 \%$.

\section{2 红枫湖水体温度和溶解氧的季节变化特征}

红枫湖表层水温变化与气温变化基本一致,全年水温变化较小. 2010 年冬季湖泊大坝、大桥和南湖中部 湖区底层和表层水温无明显差异, 呈现均匀状态, 湖泊底部水温在 $14.5 \sim 15.0^{\circ} \mathrm{C}$ 之间 (图 3). 后五湖区表层 水温略高于下部水体,温差约为 $1.5^{\circ} \mathrm{C} .2011$ 年春季,随着气温的升高,湖泊上层和下层水温出现差异, 水深 最大的大坝湖区表层水体与底层水体温差最大,达到 $13.6^{\circ} \mathrm{C}$; 湖泊底部水温在 $11.2 \sim 21.9^{\circ} \mathrm{C}$ 之间. 与 2010 年冬季类似,后五湖区表层水体温度略高于其他三个湖区. 2011 年夏季和秋季,湖泊温度维持上高下低的分 
层结构,表层水体和底部水体的温差与水深相关. 2010 年冬季至 2011 年秋季,水深最大的大坝湖区水体底 部水温在 $14.8 \sim 18.6^{\circ} \mathrm{C}$ 之间, 温差仅为 $3.8^{\circ} \mathrm{C}$. 大桥、后五和南湖中部水体底部水温多在 $14.5 \sim 23.5^{\circ} \mathrm{C}$ 之 间,反映湖泊沉积物上覆水的温度变化较大.

红枫湖溶解氧 “上高下低”, 具有显著的季节性分层特征 ${ }^{[17-18]}$. 2011 年夏季湖泊四个湖区表层水体溶解 氧在 $6.3 \sim 9.6 \mathrm{mg} / \mathrm{L}$ 之间, 均值为 $8.0 \mathrm{mg} / \mathrm{L}$. 同期, 湖泊底部水体溶解氧在 $0.2 \sim 3.6 \mathrm{mg} / \mathrm{L}$ 之间, 均值为 $1.9 \mathrm{mg} / \mathrm{L} .2010$ 年冬季湖泊四个湖区底部水体溶解氧与上部水体无明显差异, 在 $4.8 \sim 5.7 \mathrm{mg} / \mathrm{L}$ 之间, 为全 年最高值,这与秋、冬季湖区水体垂直交换有关. 2011 年春季至 2011 年秋季,水深最大的大坝湖区水体底部 溶解氧均低于 $0.2 \mathrm{mg} / \mathrm{L}$. 其他湖区水深较浅,但水体底部溶解氧最高值均低于 $1.5 \mathrm{mg} / \mathrm{L}$ (图 3 ). 显然,红枫 湖下层滞水带处于季节性的缺氧或厌氧状态.

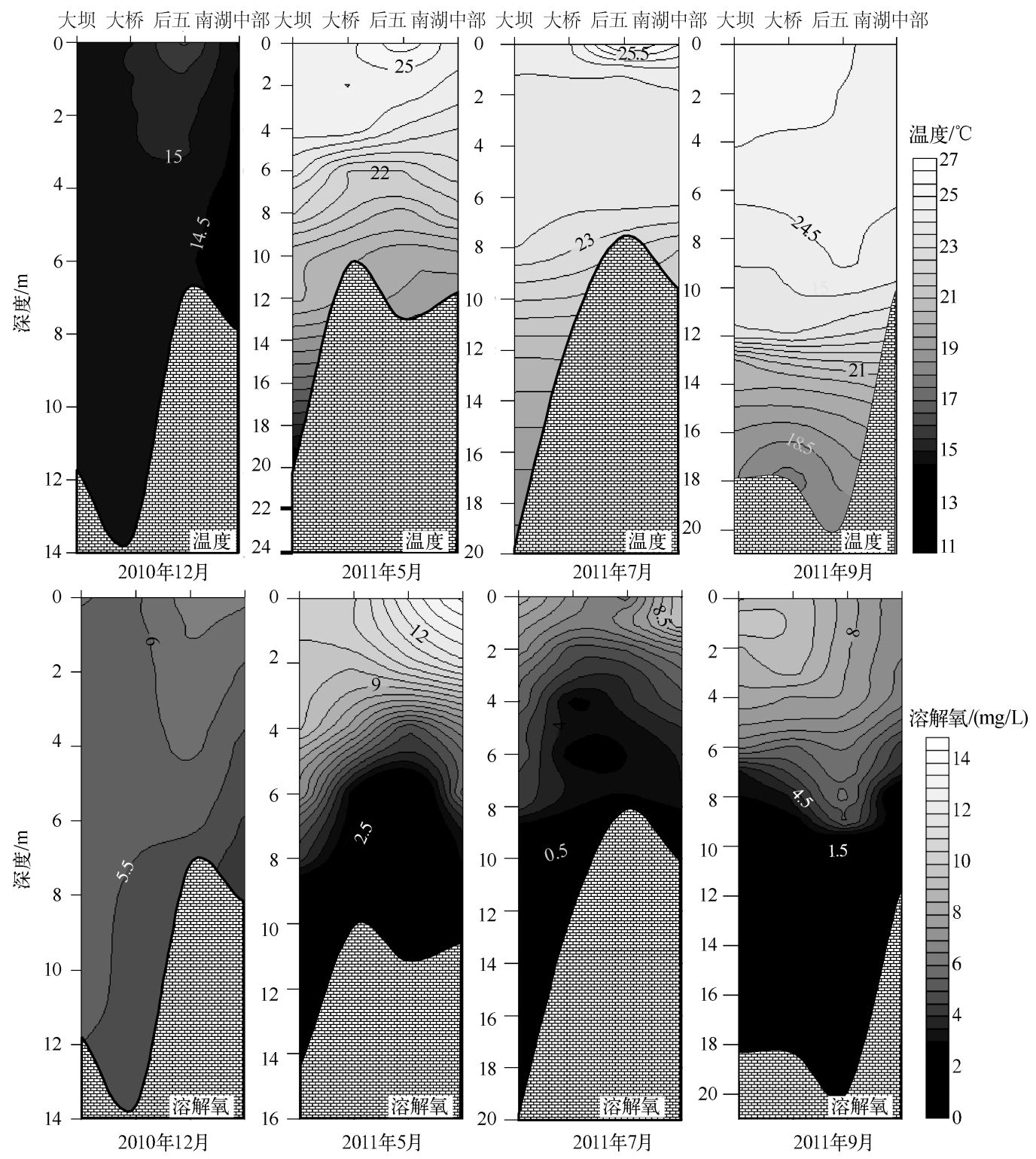

图 3 红枫湖水体温度和溶解氧的季节变化

Fig. 3 Seasonal variations of temperature and dissolved oxygen in water body in Lake Hongfeng 


\section{3 讨论}

\section{1 红枫湖沉积物总磷及赋存形态的剖面和水平空间分布特征}

红枫湖地处人为活动高强度地区, 流域人口密度高出贵州全省平均值 $80 \%$ 左右. 建库以来, 流域内工农 业污废水、生活污水排放及湖面投饵养殖等导致湖体污染严重 ${ }^{[18]}$, 湖区沉积物氮、磷等营养盐负荷较高且空 间差异显著 ${ }^{[16,19]}$.

后五湖区是红枫湖最早开展网箱养鱼的区域,直至 1990s 因湖区水质恶化才被禁止. 饵料残渣和鱼类粪 便直接或间接沉降到水体底部, 不同赋存形态的磷酸盐与碳酸锎共沉淀或被氧化铁胶体吸附 ${ }^{[2]}$, 最终沉积 在湖底,使得该区成为全湖沉积物磷、氮和有机质污染最为严重的区域. 该区表层沉积物总磷含量高,均值 超过 $2500 \mathrm{mg} / \mathrm{kg}$, 最高值达 $10021 \mathrm{mg} / \mathrm{kg}^{[19]} .21 \mathrm{~cm}$ 深度之下的沉积物是筑坝建库后淹没的原坡地和农田土 壤, 其总磷和各形态磷含量在剖面上均表现为突然的大幅降低. 后五湖区表层沉积物磷以 NaOH-SRP 为主, 占沉积物总磷的 $51.2 \% \sim 67.2 \%$ (图 2). 网箱养鱼活动被禁止之后, 表层沉积物总磷含量比网箱养鱼时期形 成的沉积物总磷含量降低了约 20\% 25\% , 且主要是由 NaOH-SRP 的大幅减少所致. 此外, 对氧化还原条件 敏感的 BD-P 和被松散颗粒物吸附的 $\mathrm{NH}_{4} \mathrm{Cl}-\mathrm{P}$ 含量也明显降低,而 rest-P 的含量变化不显著. 后五新生沉积 物中磷赋存形态及总量与网箱养鱼时期相比所发生的变化充分表明投㙁养殖给沉积物带来了巨大的污染 负荷, 且显著增加了内源磷释放风险. 同时, 后五表层沉积物磷赋存形态与南湖中部和羊昌河湖区沉积物磷 赋存形态相似,说明目前整个南湖表层沉积物中磷可能来自同一污染源或者受到同一因素影响.

工业废水排放使得新生沉积物氮、磷营养盐大量累积, 是造成湖泊内源污染负荷剧增的主要原因之一. 红枫湖南北主要人湖河流羊昌河和桃花源河的中下游各有一家化工企业,长期排放含磷、含氮废水,导致营 养盐在水体和湖区沉积物中富集. 红枫湖沉积物总磷普遍较高, 羊昌河、南湖中部、北湖中部和大坝新生表 层沉积物总磷含量在 $1500 \mathrm{mg} / \mathrm{kg}$ 以上, 以 $\mathrm{NaOH}-\mathrm{SRP}$ 为主要赋存形态 (图 2), 这与人湖河流携带的含磷工 业废水有直接关系. 大坝湖区是全湖唯一出水口,也是全湖水深最大的湖区,因筑坝的拦截作用湖区淤泥厚 度大,氮、磷营养盐在此大量累积, 使得该区成为全湖除后五以外污染最严重的湖区. 大坝沉积物磷以 NaOH-SRP和 rest-P 为主,两者之和占沉积物总磷的比例在 38.5\% $58.8 \%$ 之间,均值为 $50.3 \%$.

桃花源河沉积物柱芯采集于主要化工企业排污口的上游河段,由于未受工业废水影响其沉积物总磷在 剖面上无明显的变化,均值仅为 $990.3 \mathrm{mg} / \mathrm{kg}$, 明显低于其他湖区沉积物, 呈现与其他沉积物柱芯磷赋存形 态截然不同的垂向分布规律. 该区沉积物磷以 rest-P 为主, NaOH-SRP 含量在 $315.0 \sim 434.0 \mathrm{mg} / \mathrm{kg}$ 之间,均 值为 $380.1 \mathrm{mg} / \mathrm{kg}$.

\section{2 深水环境对沉积物磷赋存形态及释放的影响}

浅水湖泊通常不存在水体分层现象, 沉积物一水界面相互作用强烈, 同时大型水生植物对界面系统有重 要影响, 磷在沉积物一水界面发生着剧烈的生物地球化学循环 ${ }^{[21]}$. 与此相反, 深水湖泊往往存在季节性分 层,从而阻隔了表水层与较冷的深水层及沉积物之间的联系, 且大型水生植物仅分布在岸边水浅的边缘区 域, 对生态系统的影响相对较小. 与太湖和滇池等浅水湖泊相比,红枫湖沉积物中 $\mathrm{NH}_{4} \mathrm{Cl}-\mathrm{P}$ 含量较高, 这体 现出深水湖泊沉积物一水界面扰动 (包括水动力扰动和动植物生命活动引起的扰动) 较浅水湖泊弱, 沉积物 中吸附态磷释放相对缓慢 ${ }^{[21-22]}$. 红枫湖沉积物磷以 NaOH-SRP 为主, 这可能与深水型湖泊水体 $\mathrm{pH}$ 分布有密 切关系. 红枫湖水体 $\mathrm{pH}$ 总体表现为 “上高下低”,这是由于表层浮游植物的光合作用吸收 $\mathrm{CO}_{2}$ 等原因使得 $\mathrm{pH}$ 升高, 而底层有机质尤其是颗粒态有机质的降解多发生在底层而释放有机酸等使 $\mathrm{pH}$ 降低 ${ }^{[23]}$. 相比之 下,富营养化浅水湖泊浮游植物的光和作用增强时导致水体 $\mathrm{pH}$ 的上升将直接影响沉积物一水界面 $\mathrm{pH}$, 从而 促进 NaOH-SRP 的释放 ${ }^{[21]}$. 因此,红枫湖沉积物中 $\mathrm{NaOH}-\mathrm{SRP}$ 磷占总磷的比例远高于太湖和滇池等浅水湖 泊. HCl-P 磷被认为是沉积物中较为稳定的磷赋存形态,永久埋藏于沉积物中而难以被藻类等浮游生物所利 用 ${ }^{[12,24-25]}$. 红枫湖沉积物钻结合态磷绝对含量与太湖等浅水湖泊相当,在垂向上含量变化不显著.

深水湖泊沉积物中磷的释放主要随季节变化呈现周期性的变化 ${ }^{[17]}$. 温度对 DIP 的吸附/解吸平衡浓度 影响较为明显, 温度差别越大, 吸附/解吸平衡浓度的变化规律越明显 ${ }^{[26]}$. 研究表明,红枫湖水体温度上高下 低,一般湖区底部水温多在 $14.5 \sim 23.5^{\circ} \mathrm{C}$ 之间, 随季节变化底部水温差异明显. 夏季, 较高的温度条件下, 沉 
积物一水界面物质化学活性和微生物生命活动有所增强, 沉积物中有机结合态的磷可能随有机质的降解被 释放到上覆盖水体中. 同时, 微生物活动的增强, 可能会在一定尺度上改变沉积物间隙水和上覆水的 $\mathrm{pH}$ 值. $\mathrm{pH}$ 值是影响沉积物磷释放的重要因素 ${ }^{[2,27]}$, 碱性条件下, 促进 $\mathrm{NaOH}-\mathrm{SRP}$ (主要指 $\mathrm{Fe} / \mathrm{Al}$ 结合态磷) 的释放, 酸性条件下, 促进 HCl-P(主要指 $\mathrm{Ca}$ 结合态磷) 的释放. 根据化学热力学计算, 水体 $\mathrm{pH}$ 值大于 8.17 将会发 生 $\mathrm{OH}^{-}$与 $\mathrm{PO}_{4}^{3-}$ 竞争 $\mathrm{Fe}(\mathrm{III})$ 的配体, 促使磷释放行为的发生 ${ }^{[2]}$. 红枫湖水体 $\mathrm{pH}$ 值一般在 7.6 8.9 之间, 沉 积物磷因 $\mathrm{pH}$ 值导致赋存形态变化并最终导致内源磷释放是完全可能发生的.

溶解氧含量是影响磷在水一沉积物界面交换过程的重要因素 ${ }^{[28-31]}$, 其在湖泊水体的垂直分布与水体的 温度、复氧状况、生物呼吸和光合作用有关. 一般认为, 水体底部的溶解氧可决定沉积物一水界面磷的迁移转 化方向, 氧化还原电位被认为是 NaOH-SRP 能否发生释放的转折点 ${ }^{[28]}$. 富氧环境, 泥水界面处于氧化状态, 三价铁离子与磷结合, 以磷酸盐形式沉淀, 利于沉积物对上覆水中磷酸盐的吸附 ${ }^{[30]}$. 厌氧和缺氧环境, 不溶 性 $\mathrm{Fe}(\mathrm{OH})_{3}$ 变成可溶性的 $\mathrm{Fe}(\mathrm{OH})_{2}$, 使 $\mathrm{NaOH}-\mathrm{SRP}$ 释放进人水体 ${ }^{[2,29]}$. 一般来讲,浅水湖泊水体底部溶解氧 较深水湖泊略高, 相对富氧. 而深水湖泊复氧程度差, 近沉积物一水界面处水体往往处于缺氧甚至厌氧状态, 上覆水和表层间隙水中 $\mathrm{Fe}$ ( II )、 $\mathrm{NH}_{4}^{+}-\mathrm{N}$ 和 $\mathrm{S}^{2-}$ 等容易发生变化 ${ }^{[28]}$. 研究表明,红枫湖全年大多数时期水深 最大的大坝湖区水体底部溶解氧均低于 $0.2 \mathrm{mg} / \mathrm{L}$, 其他湖区水体底部溶解氧最高值通常不高于 $1.5 \mathrm{mg} / \mathrm{L}$, 秋季因上下水体发生混合导致底部溶解氧一定时期的突发性升高, 湖泊底部水体整体处于季节性的缺氧或 厌氧状态. 而 $\mathrm{NaOH}-\mathrm{SRP}$ 是红枫湖沉积物磷最主要的赋存形态 ${ }^{[16,32]}$, 在季节性分层、底部缺氧和突发性水质 恶化频发的亚深水一深水湖区内源磷释放风险较大.

\section{4 结论}

1) 红枫湖沉积物总磷含量普遍较高, 表层沉积物总磷含量明显高于下部沉积物. NaOH-SRP 和 rest-P 是 沉积物磷的主要赋存形态, 两者之和占沉积物总磷的 $75 \%$ 以上. $\mathrm{NH}_{4} \mathrm{Cl}-\mathrm{P}$ 和 BD-P 表层含量最高, 随深度增 加明显降低. rest-P 绝对含量在剖面上变化不大.

2) 红枫湖地处人为活动高强度地区, 工业废水和网箱养鱼活动等大大增加了沉积物 $\mathrm{NaOH}-\mathrm{SRP}$ 的含 量. 此外,红枫湖沉积物中弱吸附态的 $\mathrm{NH}_{4} \mathrm{Cl}-\mathrm{P}$ 含量和对氧化还原条件敏感的 BD-P 也较高.

3) 红枫湖较深, 水体温度上高下低, 湖区底部水温多在 $14.5 \sim 23.5^{\circ} \mathrm{C}$ 之间, 随季节变化底部水温差异 明显, 溶解氧最高值通常不高于 $1.5 \mathrm{mg} / \mathrm{L}$, 整体处于季节性的缺氧或厌氧状态, 存在较大的 NaOH-SRP、 $\mathrm{NH}_{4} \mathrm{Cl}-\mathrm{P}$ 和 BD-P 等内源磷释放风险,在今后的研究中需大力加强对该类型湖泊沉积物内源磷释放机制、控 制因素及治理措施的研究.

\section{5 参考文献}

[ 1 ] Søndergaard M, Jensen JP, Jeppesen E. Role of sediment and internal loading of phosphorus in shallow lakes. Hydrobiologia, 2003,506 (1) : 135-145.

[2] 范成新, 张 路,包先明等. 太湖沉积物一水界面生源要素迁移机制及定量化-2 磷释放的热力学机制及源一汇转 换. 湖泊科学,2006,18(3):207-217.

[ 3 ] Marsden MW. Lake restoration by reducing external phosphorus loading: the influence of sediment phosphorus release. Freshwater Biology, 1989,21(2) : 139-162.

[ 4 ] Van der Molen DT, Boers PCM. Influence of internal loading on phosphorus concentration in shallow lakes before and after reduction of the external loading. Hydrobiologia, 1994,275 (1) : 379-389.

[ 5 ] Rockwell DC, Warren GJ, Bertram PE et al. The US EPA Lake Erie indicators monitoring program 1983-2002: Trends in phosphorus, silica, and chlorophyll a in the central basin. Journal of Great Lakes Research, 2005 ,31(2) :23-34.

[ 6 ] Burger D, Hamilton D, Pilditch C et al. Benthic nutrient fluxes in a eutrophic, polymictic lake. Hydrobiologia, 2007, $\mathbf{5 8 4}(1): 13-25$.

[ 7 ] Elsbury KE, Paytan A, Ostrom NE et al. Using oxygen isotopes of phosphate to trace phosphorus sources and cycling in Lake Erie. Environmental Science and Technology, 2009,43(9):3108-3114.

[ 8 ] Ozkundakci D, Hamilton DP, Gibbs MM. Hypolimnetic phosphorus and nitrogen dynamics in a small, eutrophic lake with 
a seasonally anoxic hypolimnion. Hydrobiologia, 2011,661 : 5-20.

[ 9 ] Ruttenberg KC. Development of a sequential extraction method for different forms of phosphorus in marine sediments. Limnology and Oceanography, $1992,37: 1460-1482$.

[10］瓮焕新. 河流沉积物中磷的结合形态及其环境地球化学意义. 科学通报,1993,38(13):1219-1222.

[11] Hupfer M, Gfichter R, Giovano R et al. Transformation of phosphorus species in settling seston and during early sediment diagenesis. Aquatic Sciences, 1995,57 (4) :305-324.

[12] Kaiserli A, Voutsa D, Samara C. Phosphorus fractionation in lake sediments - Lakes Volvi and Koronia, Greece. Chemosphere, $2002, \mathbf{4 6}: 1147-1155$.

[13] 朱广伟,高 光,秦伯强等. 浅水湖泊沉积物中磷的地球化学特征. 水科学进展,2003,14(6):714-719.

[14] Kim LH, Choi E, Stenstron MK. Sediment characteristics, phosphorus types and phosphorus release rates between river and lake sediments. Chemosphere, $2003,50: 53-61$.

[15] 黄清辉, 王 否, 王子健. 中国湖泊水域中磷形态转化及其潜在生态效应研究动态. 湖泊科学, 2006,18:199-206.

[16] 朱元荣,张润宇,吴丰昌等. 红枫湖沉积物生物可利用磷的分布特征及其与粒径的相互关系. 湖泊科学, 2010, 22 (4) :513-520.

[17] 王雨春,朱 俊,马 梅等. 西南峡谷型湖泊的季节性分层与水质的突发性恶化. 湖泊科学,2005,17(1):54-60.

[18] 万国江,万恩源,陈敬安等. 深水人工湖环境生物地球化学过程研究: 以贵州红枫湖一百花湖为例. 地球与环境, $2010, \mathbf{3 8}(3): 262-270$.

[19] 陈敬安,张 维,张润宇等. 红枫湖底泥污染物空间分布特征. 武汉:第十三届国际湖泊大会论文集,2009.

[20] 李 键,张 维,陈敬安等.一种可实现不同水深条件下采样的湖泊沉积物柱芯采样装置. 地球与环境, 2011, 39 (1) : 121-124.

[21] 朱元荣. 云贵高原湖泊沉积物中氮、磷形态和生物有效性及其与富营养化关系研究 [学位论文]. 贵阳: 中国科学院 地球化学研究所, 2010 .

[22] 朱广伟,秦伯强, 高 光. 浅水湖泊沉积物磷释放的重要因子一一铁和水动力. 农业环境科学学报, 2003,22(6): 762-764.

[23] 吴丰昌. 天然有机质及其与污染物的相互作用. 北京:科学出版社,2010.

[24] Kozerski HP, Kleeberg A. The sediments and the benthic pelagic exchange in the shallow lake Muggelsee. International Review of Hydrobiology, $1998,83: 77-112$.

[25] 王晓丽,包华影, 郭博书. 黄河中下游表层沉积物磷的赋存形态及生物有效性. 生态环境学报, 2009, 18 (5): 1620-1624.

[26] 金相灿, 姜 霞, 王 琦等. 太湖梅梁湾沉积物中磷吸附解吸平衡特征的季节性变化. 环境科学学报, 2008,28(1): 24-30.

[27] 袁和忠, 沈 吉,刘恩峰等. 模拟水体 $\mathrm{pH}$ 控制条件下太湖梅梁湾沉积物中磷的释放特征. 湖泊科学, 2009,21 (5): 663-668.

[28］范成新,相崎守弘, 福岛武彦等. 霞浦湖沉积物需氧速率的研究. 海洋与湖沼, 1998,29(5):508-513.

[29] Gomez E, Durillon C, Rofes G et al. Phosphate adsorption and release from sediments of brackish lagoons: $\mathrm{pH}, \mathrm{O}_{2}$ and loading influence. Water Research, 1999,33 (10):2437-2447.

[30] 金相灿,姜 霞, 姚 扬等. 溶解氧对水质变化和沉积物吸磷过程的影响. 环境科学研究, 2004, 17:34-39.

[31] Vopel K, Gibbs M, Hickey CW et al. Modification of sediment water solute exchange by sediment-capping materials: effects on $\mathrm{O}_{2}$ and pH. Marine and Freshwater Research, 2008,59:1101-1110.

[32] Zhang RY, Wu FC, Liu CQ et al. Characteristics of organic phosphorus fractions in different trophic sediments of lakes from the middle and lower reaches of Yangtze River region and southwestern Plateau, China. Environmental Pollution, 2008,152 : 366-372. 